Article

\title{
Design, Synthesis and Antifungal Activity of Coumarin Ring-Opening Derivatives
}

\author{
Ming-Zhi Zhang, Yu Zhang, Jia-Qun Wang and Wei-Hua Zhang * \\ Jiangsu Key Laboratory of Pesticide Science, College of Sciences, Nanjing Agricultural University, \\ Nanjing 210095, China; mzzhang@njau.edu.cn (M.-Z.Z.); 2014811023@njau.edu.cn (Y.Z.); \\ 2014111011@njau.edu.cn (J.-Q.W.) \\ * Correspondence: njzhangwh@126.com; Tel.: +86-025-8439-5255
}

Academic Editor: Kamal Kumar

Received: 3 September 2016; Accepted: 13 October 2016; Published: 17 October 2016

\begin{abstract}
Based on our initial design, we synthesized two series of coumarin ring-opening derivatives by the reactions of hydrolysis and methylation. Results of antifungal screening in vitro showed that the target compounds exhibited potent activity against the six common pathogenic fungi. Compounds $\mathbf{6 b}, \mathbf{6 e}, \mathbf{6 g}, \mathbf{6 i}, \mathbf{7 b}$ and $7 \mathbf{c}$ were identified as the most active ones, and the $\mathrm{EC}_{50}$ values of these active compounds were further tested. Compared to the commonly used fungicide Azoxystrobin $(0.0884 \mu \mathrm{M})$, compounds $6 \mathbf{b}(0.0544 \mu \mathrm{M})$ and $6 \mathbf{e}(0.0823 \mu \mathrm{M})$ displayed improved activity against Botrytis cinerea.
\end{abstract}

Keywords: coumarin; strobilurin; synthesis; ring-opening reaction; antifungal activity

\section{Introduction}

Coumarin derivatives are widely distributed throughout nature as secondary metabolites from plants, and the structural modification of coumarin derivatives is a hotspot in the field of natural product chemistry [1,2]. As the structural core, coumarin occurs widely in natural products, drugs and agrochemicals (Figure 1), these important applications have generated considerable interest in this ring system and various fused coumarin derivatives have been reported [3-6]: Osthole, a natural $\mathrm{O}$-methylated coumarin found in Cnidium Monnieri, a traditional Chinese herbal medicine that has been used as as a fungicidein China for a long history, and shows antifungal activity against Rhizoctonia solani and a broad spectrum of other phytopathogenic fungi [7-9]; Warfarin and Acenocoumarol are anticoagulants normally used in the prevention of thrombosis and thromboembolism, function as the vitamin K antagonists [10-12]; and Coumoxystrobin (SYP-3375) is a coumarin-containing strobilurin fungicide that contains an (E)-methyl 3-methoxy-2-phenylacrylate substructure and displays a broad spectrum of antifungal activity [13-15].<smiles>COc1ccc2ccc(=O)oc2c1CC=C(C)C</smiles>

Osthole<smiles>CC(=O)CC(c1ccccc1)c1c(O)c2ccccc2oc1=O</smiles>

Warfarin<smiles>CC(=O)CC(c1ccc([N+](=O)[O-])cc1)c1c(O)c2ccccc2oc1=O</smiles>

Acenocoumarol

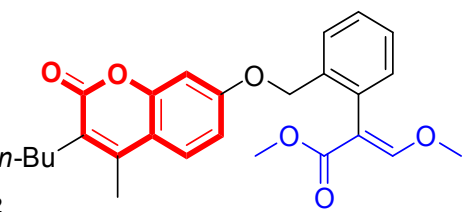

Coumoxystrobin

Figure 1. Structures of coumarin-containing drugs and agrochemicals.

In our previous work, Osthole was used as the lead structure to carry out structural optimization, and some synthesized furan[3,2-c]coumarin derivatives showed potent antifungal activity [16-18]. 
In this study, the chemical structure of coumarin can be treated as $O$-hydroxyphenylacrylate lactone, its ring-opening product contains a substructural unit of strobilurin fungicide, the pharmacophore of which is (E)-methyl 3-methoxy-2-phenylacrylate (Figure 2). According to our initial design, we synthesized two series of coumarin ring-opening derivatives differentially substituted on the benzene ring, starting from furan[3,2-c]coumarin reported as an active lead structure in our previous research [17].

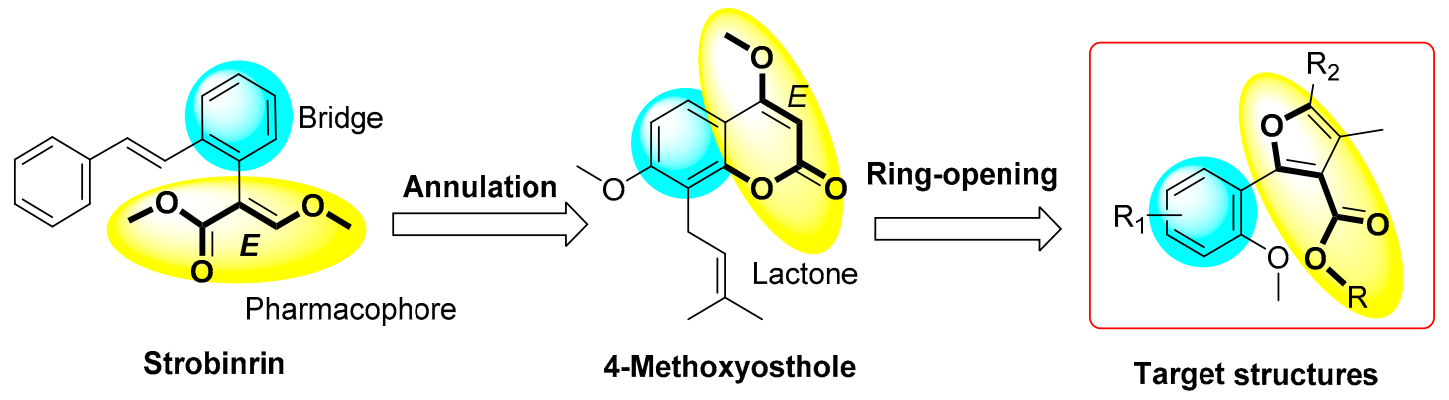

Figure 2. Design strategies of target molecules.

\section{Results and Discussion}

\subsection{Synthetic Chemistry}

Based on the reported synthetic route (Scheme 1) [19],three kinds of substituted phenols 1 and Meldrum's acid 2 were employed as the starting materials to generate the intermediate maleate 3, the resulting acetone was removed by rotavapor, then the Eaton's reagent (phosphoric anhydride + methylsulfonic acid) was added to the residue of the reaction mixture that was continuously stirred at $70{ }^{\circ} \mathrm{C}$ for $3 \mathrm{~h}$. Then, the parent structure 4-hydroxycoumarins 4 were prepared in a two-step process, which involved initial transesterification and following oxidative cyclization. Afterward, the reaction of 4-hydroxycoumarin and $\alpha$-haloketone generated furo[3,2-c]coumarin derivatives via an efficient tandem $\mathrm{O}$-alkylation/cyclisation protocol $[17,20]$. Then, furan[3,2-c]coumarin 5 was used as an intermediate to generate a compound that contains the substructure of the strobilurin fungicide by hydrolysis and methylation [21]. Two series of coumarin ring-opening derivatives 6 and 7 were synthesized efficiently in moderate to good yields (from $48 \%$ to $75 \%$ ). The reaction yields were not optimized. The structures of all target compounds 6 and 7 have been confirmed by NMR, IR and HRMS. The yields and structures are also summarized in Chemicals and Methods section.

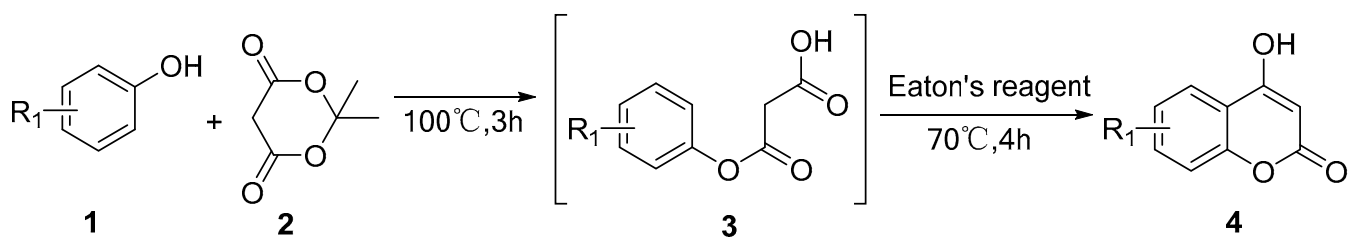<smiles>[R2]c1oc2c3c(oc(=O)c2c1C)C=C[R](C)C=C3</smiles>

5<smiles>[R][R]O[Na]</smiles><smiles>[Z]Oc1cc[R]([H])cc1-c1oc([R2])c(C)c1C(=O)OC</smiles>

Scheme 1. Synthetic routes for target compounds. 


\subsection{Antifungal Activity and the Structure-Activity Relationships (SAR)}

In general, data presented in Table 1 indicate that the coumarin ring-opening derivatives exhibit certain activities against Botrytis cinerea, Alternaria solani and Rhizoctorzia solani at $50 \mu \mathrm{M}$, especially effective to Botrytis cinerea, almost half of the synthesized compounds displayed better activity than the positive control Azoxystrobin. Although compound $7 \mathrm{c}$ demonstrated similar activity against Cucumber anthrax to Azoxystrobin, most of the target compounds showed rather poor activity against Gibberella zeae, Cucumber anthrax and Alternari amali.

Table 1. Antifungal activity of coumarin ring-opening derivatives (inhibitory rate, $\%$ ).

\begin{tabular}{|c|c|c|c|c|c|c|}
\hline \multirow{3}{*}{ Compound } & \multicolumn{6}{|c|}{ Species $^{\mathrm{a}}$} \\
\hline & BOT & ALS & GIB & RHI & RHI & ALM \\
\hline & 50 Rate $(\mu \mathrm{M})$ & 50 Rate $(\mu \mathrm{M})$ & 50 Rate $(\mu \mathrm{M})$ & 50 Rate $(\mu \mathrm{M})$ & 50 Rate $(\mu \mathrm{M})$ & 50 Rate $(\mu \mathrm{M})$ \\
\hline $6 a$ & $60.3^{b}$ & 38.0 & 16.7 & 31.2 & $-{ }^{c}$ & 7.8 \\
\hline $6 b$ & 81.0 & 24.0 & 28.3 & 42.2 & 0 & 9.8 \\
\hline $6 c$ & 41.3 & 12.0 & 0 & 6.2 & 0 & - \\
\hline $6 \mathrm{~d}$ & 49.2 & 30.0 & 5.0 & 23.4 & 12.1 & 19.6 \\
\hline $6 e$ & 74.1 & 7.3 & 7.1 & 25.9 & 18.2 & 14.8 \\
\hline $6 f$ & 58.6 & 5.5 & 0 & 12.1 & 0 & - \\
\hline $6 \mathrm{~g}$ & 77.8 & 40.0 & 13.3 & 34.4 & - & 17.6 \\
\hline $6 \mathrm{~h}$ & 33.3 & 24.0 & 8.3 & 20.3 & 0 & - \\
\hline $6 i$ & 77.6 & 30.9 & 26.8 & 15.5 & 14.5 & 38.9 \\
\hline $7 \mathbf{a}$ & 51.7 & 20.0 & 28.6 & 37.9 & 21.8 & 22.2 \\
\hline $7 \mathrm{~b}$ & 70.7 & 23.6 & 44.6 & 51.7 & 14.5 & 33.3 \\
\hline $7 \mathrm{c}$ & 67.2 & 14.5 & 30.4 & 51.7 & 84.2 & 25.9 \\
\hline $7 \mathrm{~d}$ & 25.9 & 14.5 & 19.6 & 34.5 & 14.5 & 7.4 \\
\hline $7 e$ & 32.7 & 0 & 29.5 & 50.8 & 5.8 & 11.1 \\
\hline $7 \mathrm{f}$ & 65.5 & 20.0 & 28.6 & 27.6 & 38.2 & 24.1 \\
\hline $7 \mathrm{~g}$ & - & 9.1 & 32.1 & 39.6 & 14.5 & 16.7 \\
\hline $7 \mathrm{~h}$ & 10.3 & - & 17.8 & 13.8 & 0 & 0 \\
\hline $7 \mathbf{i}$ & & 0 & 14.3 & 8.6 & 0 & 16.7 \\
\hline Azoxystrobin & 50.4 & 31.3 & 58.2 & 60.7 & 89.9 & 44.5 \\
\hline
\end{tabular}

${ }^{a}$ BOT, Botrytis cinerea; ALS, Alternariasolani; GIB, Gibberellazeae; RHI, Rhizoctorziasolani; CUC, Cucumber anthrax;

ALM, Alternariamali. ${ }^{\mathrm{b}}$ All data are the average value of three replications. ${ }^{\mathrm{c}}$ Test failure or not test.

As eight compounds $(\mathbf{6 a}, \mathbf{6 b}, \mathbf{6 e}, \mathbf{6 g}, \mathbf{6 i}, \mathbf{7 b}, \mathbf{7 c}$ and $\mathbf{7 f})$ showed relatively effective control against Botrytis cinerea and/or Rhizoctorzia solani, we further tested the $\mathrm{EC}_{50}$ values of these compounds together with Azoxystrobin. As shown in Table 2, we noticed that the $\mathrm{EC}_{50}$ values of compounds $\mathbf{6 b}$ and 6e were as low as 0.0544 and $0.0823 \mu \mathrm{M}$ against Botrytis cinerea, respectively, which proves it is more effective than Azoxystrobin $(0.0884 \mu \mathrm{M})$. Compound $7 \mathbf{b}(0.137 \mu \mathrm{M})$ and $7 \mathbf{c}(0.182 \mu \mathrm{M})$ exhibited equivalent antifungal activity with Azoxystrobin $(0.122 \mu \mathrm{M})$ against Rhizoctorzia solani. Compounds $\mathbf{6 b}, 6 \mathrm{e}, \mathbf{6 g}, \mathbf{6 i}, \mathbf{7 b}$ and $7 \mathrm{c}$ were identified as the most active ones among the synthesized coumarin ring-opening derivatives, as shown in Figure 3.

Table 2. $\mathrm{EC}_{50}$ determination of some active compounds.

\begin{tabular}{cccccc}
\hline Pathogen & Compound & Toxic Regression & $\mathbf{R}$ & $\mathbf{E C}_{\mathbf{5 0}}(\boldsymbol{\mu M})$ & $\mathbf{9 5 \%}$ Confidence Interval \\
\hline BOT & $\mathbf{6 a}$ & $\mathrm{Y}=2.4538+1.7909 \mathrm{x}$ & 0.9905 & 0.1130 & $0.0966-0.1330$ \\
BOT & $\mathbf{6 b}$ & $\mathrm{Y}=3.3419+1.4690 \mathrm{x}$ & 0.9994 & 0.0544 & $0.0523-0.0566$ \\
BOT & $\mathbf{6 e}$ & $\mathrm{Y}=2.6307+1.7429 \mathrm{x}$ & 0.9932 & 0.0823 & $0.0724-0.0942$ \\
BOT & $\mathbf{6 g}$ & $\mathrm{Y}=2.1175+2.1486 \mathrm{x}$ & 0.9768 & 0.0889 & $0.0696-0.1130$ \\
BOT & $\mathbf{6 i}$ & $\mathrm{Y}=1.9225+2.1902 \mathrm{x}$ & 0.9779 & 0.0901 & $0.0699-0.1160$ \\
BOT & $\mathbf{7 b}$ & $\mathrm{Y}=2.0301+2.0457 \mathrm{x}$ & 0.9942 & 0.1090 & $0.0964-0.1230$ \\
BOT & $\mathbf{7 c}$ & $\mathrm{Y}=1.7715+2.0569 \mathrm{x}$ & 0.9980 & 0.1290 & $0.1200-0.1380$ \\
BOT & $\mathbf{7 f}$ & $\mathrm{Y}=0.9264+2.6215 \mathrm{x}$ & 0.9954 & 0.1120 & $0.1010-0.1250$ \\
BOT & Azoxystrobin & $\mathrm{Y}=3.5635+0.9256 \mathrm{x}$ & 0.9998 & 0.0884 & $0.0858-0.0910$ \\
RHI & $\mathbf{7 b}$ & $\mathrm{Y}=3.3881+1.0377 \mathrm{x}$ & 0.9994 & 0.1370 & $0.1320-0.1430$ \\
RHI & $\mathbf{7 c}$ & $\mathrm{Y}=2.0840+1.6967 \mathrm{x}$ & 0.9950 & 0.1820 & $0.1610-0.2050$ \\
RHI & Azoxystrobin & $\mathrm{Y}=3.4242+0.9321 \mathrm{x}$ & 0.9981 & 0.1220 & $0.1050-0.1410$ \\
\hline
\end{tabular}


<smiles>Cc1oc(-c2ccccc2O)c(C(=O)O)c1C</smiles>

6b

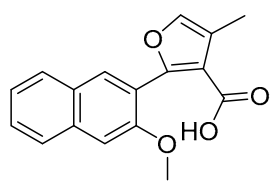

$6 \mathbf{i}$<smiles>COc1ccc(-c2oc(C)c(C)c2C(=O)O)c(OC)c1</smiles>

$6 e$<smiles>COC(=O)c1c(-c2ccccc2OC)oc(C)c1C</smiles>

$7 b$<smiles>COc1ccc(C)cc1-c1occ(C)c1C(=O)O</smiles>

$6 \mathrm{~g}$<smiles>COC(=O)c1c(-c2ccccc2OC)oc(C(C)=O)c1C</smiles>

$7 c$

Figure 3. Structures of the most active coumarin ring-opening derivatives.

Although the antifungal activity of most of the coumarin ring-opening derivatives has been proven to be rather poor, making it difficult to extract a clear SAR analysis, some broad conclusions still can be drawn from the presented data in Table 1. Firstly, these coumarin ring-opening compounds were noticeably more active against Botrytis cinerea than against the five other phytopathogenic fungi. Half of the target compounds displayed better or equivalent activity to the positive control Azoxystrobin. This is highlighted by compounds $6 \mathbf{b}, \mathbf{6 e}, \mathbf{6 g}$ and $6 \mathbf{i}$. Secondly, the antifungal activity of target compounds varied with the alternation of substituting groups at the benzene ring, as a tentative conclusion, it has a beneficial effect when the $\mathrm{R}_{1}$ was $\mathrm{H}$ rather than the other substituents, illustrated by the fact that compounds $\mathbf{6 a - 6 c}$, and $\mathbf{7 a - 7 c}$ generally showed better control against most of the tested fungi than the other compounds.

\section{Materials and Methods}

\subsection{Chemicals and Methods}

All chemicals including substituted phenols, Meldrum's acid, Eaton's reagent and 4-Hydroxycoumarin 4a were purchased from commercial sources (e.g., Crystal Chemicals, Nanjing, China, and Alfa Aesar, Beijing, China) and used without further purification unless otherwise stated. The course of reactions and the purity of products were monitored by TLC using silica gel GF/UV 254. The melting points of these coumarin ring-opening derivatives were determined on an X-4 apparatus (uncorrected), which was bought from Shanghai Tech (Shanghai, China). Nuclear magnetic resonance $\left({ }^{1} \mathrm{H}\right.$ - and $\left.{ }^{13} \mathrm{C}-\mathrm{NMR}\right)$ spectra were obtained using a Bruker Avance $400 \mathrm{MHz}$ spectrometer (Bruker Biospin Co., Stuttgart, Germany) in $\mathrm{CDCl}_{3}$ solution with TMS as an internal standard. Infrared (IR) spectra were recorded on a Bruker Tensor 27 spectrometer (Bruker Biospin Co.), and samples were prepared as $\mathrm{KBr}$ plates. High Resolution Mass Spectrometer (HRMS) spectra were carried out with a ThermoExactive spectrometer (ThermoFisher Scientific Inc., Waltham, MA, USA).

\subsubsection{General Procedure for the Synthesis of Compound 4 (Scheme 1)}

A mixture of substituted phenol $(0.094 \mathrm{~g}, 1.0 \mathrm{mmol})$ and Meldrum's acid $(0.144 \mathrm{~g}, 1.0 \mathrm{mmol})$ was stirred at $100{ }^{\circ} \mathrm{C}$ for $3 \mathrm{~h}$ (monitored by TLC), then the small remaining amount of acetone was removed by vacuum. Eaton's reagent $(3 \mathrm{~mL})$ was added to the mixture at $70{ }^{\circ} \mathrm{C}$ for $4 \mathrm{~h}$. Then, water was added to this mixture while stirring vigorously. The precipitate was filtered by suction, washed with water, and dried to give a crude product. It was recrystallized from ethanol to afford compounds $\mathbf{4} \mathbf{b}-\mathbf{4} \mathbf{d}$. (4-Hydroxycoumarin 4a was obtained from a commercial source).

4-Hydroxy-7-methoxy-2H-chromen-2-one (4b): white solid, yield 74\%, m.p. $264.0-264.5{ }^{\circ} \mathrm{C} .{ }^{1} \mathrm{H}-\mathrm{NMR}$ $\left(300 \mathrm{MHz}, \mathrm{DMSO}-d_{6}\right) \delta 12.36(\mathrm{~s}, 1 \mathrm{H}), 7.70(\mathrm{dd}, J=8.4,0.7 \mathrm{~Hz}, 1 \mathrm{H}), 6.96-6.86(\mathrm{~m}, 2 \mathrm{H}), 5.43(\mathrm{~s}, 1 \mathrm{H}), 3.83$ $(\mathrm{s}, 3 \mathrm{H})$. 
4-Hydroxy-6-methyl-2H-chromen-2-one (4c): light yellow solid, yield 54\%, m.p. $260.1-261.3{ }^{\circ} \mathrm{C} ;{ }^{1} \mathrm{H}-\mathrm{NMR}$ $\left(400 \mathrm{MHz}, \mathrm{DMSO}-d_{6}\right) \delta 12.47(\mathrm{~s}, 1 \mathrm{H}), 7.62(\mathrm{~d}, J=2.1 \mathrm{~Hz}, 1 \mathrm{H}), 7.46(\mathrm{dd}, J=8.4,2.1 \mathrm{~Hz}, 1 \mathrm{H}), 7.27(\mathrm{~d}$, $J=8.5 \mathrm{~Hz}, 1 \mathrm{H}), 5.57(\mathrm{~s}, 1 \mathrm{H}), 2.38(\mathrm{~s}, 3 \mathrm{H})$.

4-Hydroxy-2H-benzo[g]chromen-2-one (4d): white solid, yield 51\%, m.p. $188.5-186.0{ }^{\circ} \mathrm{C} ;{ }^{1} \mathrm{H}-\mathrm{NMR}$ $\left(400 \mathrm{MHz}\right.$, Acetone- $\left.d_{6}\right) \delta 8.51-8.43(\mathrm{~m}, 1 \mathrm{H}), 8.08-8.01(\mathrm{~m}, 1 \mathrm{H}), 7.94-7.81(\mathrm{~m}, 2 \mathrm{H}), 7.78-7.69(\mathrm{~m}, 2 \mathrm{H}), 5.79$ $(\mathrm{s}, 1 \mathrm{H})$.

\subsubsection{General Procedure for the Synthesis of Compound 5 (Scheme 1)}

To a stirring solution of substituted 4-hydroxycoumarin 4 (10 mmol) and ammonium acetate $(7.7 \mathrm{~g}, 100 \mathrm{mmol})$ in toluene $(50 \mathrm{~mL})$ and acetic acid $(5 \mathrm{~mL})$ was added cholroacetone $(5 \mathrm{~mL}, 62 \mathrm{mmol})$ or 3-chlorobutan-2-one, and 3-chloropentane-2,4-dione $(62 \mathrm{mmol})$ in a single portion via syringe. The mixture was stirred under reflux for about 10 huntil full conversion of the substrates was indicated by TLC analysis, and then cooled to room temperature and concentrated at reduced pressure. Then $50 \mathrm{~mL}$ saturated brine solution was added to the mixture and extracted with EtOAc three times $(3 \times 50 \mathrm{~mL})$, the extract was washed with $10 \% \mathrm{NaHCO}_{3}$ solution, organic phase was dried over anhydrous $\mathrm{Na}_{2} \mathrm{SO}_{4}$, and concentrated under reduced pressure. The crude product was purified by silica gel column chromatography using petroleum ether/acetone (20:1 to 5:1) as eluent to give the compound 5 (Table 3).

Table 3. The yields and structures of compound 5 .

\begin{tabular}{cccccccc}
\hline Compound & $\mathbf{R}_{\mathbf{1}}$ & $\mathbf{R}_{\mathbf{2}}$ & Yield & Compound & $\mathbf{R}_{\mathbf{1}}$ & $\mathbf{R}_{\mathbf{2}}$ & Yield \\
\hline $5 \mathrm{a}$ & $\mathrm{H}$ & $\mathrm{H}$ & $79 \%$ & $5 \mathrm{~g}$ & $8-\mathrm{Me}$ & $\mathrm{H}$ & $67 \%$ \\
$5 \mathrm{~b}$ & $\mathrm{H}$ & $\mathrm{Me}$ & $38 \%$ & $5 \mathrm{~h}$ & $8-\mathrm{Me}$ & $\mathrm{Ac}$ & $34 \%$ \\
$5 \mathrm{c}$ & $\mathrm{H}$ & $\mathrm{Ac}$ & $33 \%$ & $5 \mathrm{i}$ & $7,8-(\mathrm{CH})_{4}$ & $\mathrm{H}$ & $55 \%$ \\
$5 \mathrm{~d}$ & $7-\mathrm{OMe}$ & $\mathrm{H}$ & $79 \%$ & $5 \mathrm{j}$ & $7,8-(\mathrm{CH})_{4}$ & $\mathrm{Me}$ & $37 \%$ \\
$5 \mathrm{e}$ & $7-\mathrm{OMe}$ & $\mathrm{Me}$ & $22 \%$ & $5 \mathrm{k}$ & $7,8-(\mathrm{CH})_{4}$ & $\mathrm{Ac}$ & $45 \%$ \\
$5 \mathrm{f}$ & $7-\mathrm{OMe}$ & $\mathrm{Ac}$ & $36 \%$ & & & & \\
\hline
\end{tabular}

3-Methyl-4H-furo[3,2-c]chromen-4-one (5a): white solid, m.p. $155.7-156.3{ }^{\circ} \mathrm{C} ;{ }^{1} \mathrm{H}-\mathrm{NMR}(400 \mathrm{MHz}$, Chloroform-d) $\delta 7.87(\mathrm{dd}, J=7.8,1.6 \mathrm{~Hz}, 1 \mathrm{H}), 7.52(\mathrm{ddd}, J=8.6,7.1,1.6 \mathrm{~Hz}, 1 \mathrm{H}), 7.47-7.40(\mathrm{~m}, 2 \mathrm{H}), 7.35$ $(\mathrm{td}, J=7.5,1.2 \mathrm{~Hz}, 1 \mathrm{H}), 2.39(\mathrm{~d}, J=1.4 \mathrm{~Hz}, 3 \mathrm{H}) ;{ }^{13} \mathrm{C}-\mathrm{NMR}\left(101 \mathrm{MHz}, \mathrm{DMSO}-d_{6}\right) \delta 158.07,157.30,152.43$, $143.13,131.35,125.23,121.11,119.81,117.36,112.83,110.42,8.66 . \mathrm{IR}(\mathrm{KBr}) \vee\left(\mathrm{cm}^{-1}\right) 3046,2927,1742$, 1632, 1581, 1548, 1502, 1445; HR-MS (ESI): $m / z$ calcd for $\mathrm{C}_{12} \mathrm{H}_{8} \mathrm{O}_{3}\left([\mathrm{M}+\mathrm{H}]^{+}\right)$201.0552, found 201.0546.

2,3-Dimethyl-4H-furo[3,2-c]chromen-4-one (5b): white solid, m.p. $183.8-184.1{ }^{\circ} \mathrm{C} ;{ }^{1} \mathrm{H}-\mathrm{NMR}(400 \mathrm{MHz}$, Chloroform- $d) \delta 7.83(\mathrm{dd}, J=7.8,1.5 \mathrm{~Hz}, 1 \mathrm{H}), 7.5-7.38(\mathrm{~m}, 2 \mathrm{H}), 7.33(\mathrm{ddd}, J=8.2,7.2,1.4 \mathrm{~Hz}, 1 \mathrm{H})$, $2.42(\mathrm{~d}, J=1.0 \mathrm{~Hz}, 3 \mathrm{H}), 2.30(\mathrm{~d}, J=1.1 \mathrm{~Hz}, 3 \mathrm{H}) ;{ }^{13} \mathrm{C}-\mathrm{NMR}(101 \mathrm{MHz}$, Chloroform-d $) \delta 158.84,155.57$, $152.22,150.82,129.79,124.24,120.38,117.08,114.06,113.08,111.31,11.51,8.52 ; \mathrm{IR}(\mathrm{KBr}) v\left(\mathrm{~cm}^{-1}\right) 3062$, 2956, 1756, 1634, 1619, 1592, 1568, 1439; HR-MS (ESI): $m / z$ calcd for $\mathrm{C}_{13} \mathrm{H}_{10} \mathrm{O}_{3}\left([\mathrm{M}+\mathrm{H}]^{+}\right)$215.0708, found 215.0702 .

2-Acetyl-3-methyl-4H-furo[3,2-c]chromen-4-one (5c): light yellow solid, m.p. 178.6-178.9 ${ }^{\circ} \mathrm{C} ;{ }^{1} \mathrm{H}-\mathrm{NMR}$ $(400 \mathrm{MHz}$, Chloroform-d) $\delta 7.99$ (dd, $J=7.8,1.5 \mathrm{~Hz}, 1 \mathrm{H}), 7.63$ (ddt, $J=8.5,7.1,1.2 \mathrm{~Hz}, 1 \mathrm{H}), 7.48(\mathrm{~d}$, $J=8.4 \mathrm{~Hz}, 1 \mathrm{H}), 7.45-7.38(\mathrm{~m}, 1 \mathrm{H}), 2.76(\mathrm{~d}, J=1.0 \mathrm{~Hz}, 3 \mathrm{H}), 2.65(\mathrm{~d}, J=0.9 \mathrm{~Hz}, 3 \mathrm{H}) ;{ }^{13} \mathrm{C}-\mathrm{NMR}(101 \mathrm{MHz}$, Chloroform- $d$ ) $\delta 188.67,157.76,157.31,153.67,149.14,132.25,129.53,124.80,121.55,117.54,112.13$, 111.98, 27.63, 10.23; IR (KBr) v $\left(\mathrm{cm}^{-1}\right)$ 3028, 2922, 1736, 1674, 1625, 1596, 1545, 1427; HR-MS (ESI): $m / z$ calcd for $\mathrm{C}_{14} \mathrm{H}_{10} \mathrm{O}_{4}\left([\mathrm{M}+\mathrm{H}]^{+}\right)$243.0657, found 243.0651 .

7-Methoxy-3-methyl-4H-furo[3,2-c]chromen-4-one (5d): light yellow solid, m.p.150.7-151.0 ${ }^{\circ} \mathrm{C} ;{ }^{1} \mathrm{H}-\mathrm{NMR}$ $\left(400 \mathrm{MHz}, \mathrm{DMSO}-d_{6}\right) \delta 7.84(\mathrm{~d}, J=8.6 \mathrm{~Hz}, 1 \mathrm{H}), 7.29(\mathrm{~d}, J=2.2 \mathrm{~Hz}, 1 \mathrm{H}), 7.17(\mathrm{dd}, J=8.6,2.2 \mathrm{~Hz}, 1 \mathrm{H})$, 
$5.91(\mathrm{~s}, 1 \mathrm{H}), 4.02(\mathrm{~s}, 3 \mathrm{H}), 2.32(\mathrm{~s}, 3 \mathrm{H}) ; \mathrm{IR}(\mathrm{KBr}) \vee\left(\mathrm{cm}^{-1}\right)$ 3076, 2920, 1743, 1625, 1600, 1580, 1553, 1446; HR-MS (ESI): $m / z$ calcd for $\mathrm{C}_{13} \mathrm{H}_{10} \mathrm{O}_{4}\left([\mathrm{M}+\mathrm{H}]^{+}\right)$231.0657, found 231.0652 .

7-Methoxy-2,3-dimethyl-4H-furo[3,2-c]chromen-4-one (5e): white solid, m.p.143.5-144.0 ${ }^{\circ} \mathrm{C} ;{ }^{1} \mathrm{H}-\mathrm{NMR}$ $(400 \mathrm{MHz}$, Chloroform- $d) \delta 7.72(\mathrm{~d}, J=8.5 \mathrm{~Hz}, 1 \mathrm{H}), 6.96-6.88(\mathrm{~m}, 2 \mathrm{H}), 3.89(\mathrm{~s}, 3 \mathrm{H}), 2.39(\mathrm{~d}, J=1.1 \mathrm{~Hz}$, 3H), $2.28(\mathrm{~d}, J=1.1 \mathrm{~Hz}, 3 \mathrm{H}) ;{ }^{13} \mathrm{C}-\mathrm{NMR}(101 \mathrm{MHz}$, Chloroform-d $) \delta 161.34,159.15,156.31,153.94,149.73$, 121.33, 113.65, 112.42, 108.96, 106.60, 101.26, 55.68, 11.42, 8.53; IR (KBr) $\vee\left(\mathrm{cm}^{-1}\right)$ 3030, 2950, 1748, 1631, 1602, 1511, 1439; HR-MS (ESI): $m / z$ calcd for $\mathrm{C}_{14} \mathrm{H}_{12} \mathrm{O}_{4}\left([\mathrm{M}+\mathrm{H}]^{+}\right)$245.0814, found 245.0806.

2-Acetyl-7-methoxy-3-methyl-4H-furo[3,2-c]chromen-4-one (5f): orange solid, m.p. 203.0-204.6 ${ }^{\circ} \mathrm{C}$; ${ }^{1} \mathrm{H}-\mathrm{NMR}(400 \mathrm{MHz}$, Chloroform-d) $\delta 7.87(\mathrm{~d}, J=8.6 \mathrm{~Hz}, 1 \mathrm{H}), 7.01-6.92(\mathrm{~m}, 2 \mathrm{H}), 3.93(\mathrm{~s}, 3 \mathrm{H}), 2.73$ $(\mathrm{s}, 3 \mathrm{H}), 2.62(\mathrm{~s}, 3 \mathrm{H}) ;{ }^{13} \mathrm{C}-\mathrm{NMR}(101 \mathrm{MHz}$, Chloroform- $d) \delta 188.53,163.21,158.07,158.01,155.61,148.60$, 129.76, 122.61, 113.21, 109.69, 105.35, 101.45, 55.88, 27.60, 10.28; IR (KBr) $\vee\left(\mathrm{cm}^{-1}\right) 3088,2942,1746,1672$, 1628, 1606, 1551, 1423; HR-MS (ESI): $m / z$ calcd for $\mathrm{C}_{15} \mathrm{H}_{12} \mathrm{O}_{5}\left([\mathrm{M}+\mathrm{H}]^{+}\right)$273.0763, found 273.0756.

3,8-Dimethyl-4H-furo[3,2-c]chromen-4-one (5g): light yellow solid, m.p. $141.7-143.7{ }^{\circ} \mathrm{C} ;{ }^{1} \mathrm{H}-\mathrm{NMR}$ $(400 \mathrm{MHz}$, Chloroform- $d)$ 8 7.67-7.63 (m, 1H), $7.42(\mathrm{t}, J=1.3 \mathrm{~Hz}, 1 \mathrm{H}), 7.34-7.31(\mathrm{~m}, 2 \mathrm{H}), 2.47(\mathrm{~s}, 3 \mathrm{H})$, $2.38(\mathrm{~d}, J=1.3 \mathrm{~Hz}, 3 \mathrm{H})$; IR (KBr) $v\left(\mathrm{~cm}^{-1}\right) 3064,2921,1735,1632,1583,1558,1501,1428$; HR-MS (ESI): $m / z$ calcd for $\mathrm{C}_{13} \mathrm{H}_{10} \mathrm{O}_{3}\left([\mathrm{M}+\mathrm{H}]^{+}\right)$215.0708, found 215.0702.

2-Acetyl-3,8-dimethyl-4H-furo[3,2-c]chromen-4-one (5h): orange solid, m.p. 225.6-226.0 ${ }^{\circ} \mathrm{C} ;{ }^{1} \mathrm{H}-\mathrm{NMR}$ $(400 \mathrm{MHz}$, Chloroform- $d$ ) $\delta 7.78-7.75(\mathrm{~m}, 1 \mathrm{H}), 7.42(\mathrm{dd}, J=8.5,2.0 \mathrm{~Hz}, 1 \mathrm{H}), 7.36(\mathrm{~d}, J=8.5 \mathrm{~Hz}, 1 \mathrm{H}), 2.76$ (s, 3H), $2.66(\mathrm{~s}, 3 \mathrm{H}), 2.50(\mathrm{~s}, 3 \mathrm{H}) ;{ }^{13} \mathrm{C}-\mathrm{NMR}(101 \mathrm{MHz}$, Chloroform-d) $\delta$ 188.66, 157.98, 157.41, 151.91, 149.06, 134.77, 133.32, 129.63, 121.18, 117.27, 111.90, 111.80, 27.64, 20.91, 10.26; IR (KBr) v (cm $\left.{ }^{-1}\right) 3026$, 2925, 1733, 1668, 1630, 1593, 1574, 1548, 1506, 1453; HR-MS (ESI): $m / z$ calcd for $\mathrm{C}_{15} \mathrm{H}_{12} \mathrm{O}_{4}\left([\mathrm{M}+\mathrm{H}]^{+}\right)$ 257.0814, found 257.0805.

3-Methyl-4H-benzo[g]furo[3,2-c]chromen-4-one (5i): light yellow solid, m.p. 205.0-205.3 ${ }^{\circ} \mathrm{C} ;{ }^{1} \mathrm{H}-\mathrm{NMR}$ (400 MHz, Chloroform- $d$ ) $\delta 8.67-8.59(\mathrm{~m}, 1 \mathrm{H}), 7.94-7.84(\mathrm{~m}, 2 \mathrm{H}), 7.77(\mathrm{~d}, J=8.6 \mathrm{~Hz}, 1 \mathrm{H}), 7.70-7.61$ $(\mathrm{m}, 2 \mathrm{H}), 7.46(\mathrm{q}, J=1.4 \mathrm{~Hz}, 1 \mathrm{H}), 2.43(\mathrm{~d}, J=1.3 \mathrm{~Hz}, 3 \mathrm{H}) ; \mathrm{IR}(\mathrm{KBr}) \vee\left(\mathrm{cm}^{-1}\right)$ 3028, 2920, 1730, 1617, 1578, 1489; HR-MS (ESI): $m / z$ calcd for $\mathrm{C}_{16} \mathrm{H}_{10} \mathrm{O}_{3}\left([\mathrm{M}+\mathrm{H}]^{+}\right)$251.0708, found 251.0702.

2,3-Dimethyl-4H-benzo[g]furo[3,2-c]chromen-4-one (5j): yellow solid, m.p. $238.5-239.1{ }^{\circ} \mathrm{C} ;{ }^{1} \mathrm{H}-\mathrm{NMR}$ $(400 \mathrm{MHz}$, Chloroform- $d) \delta 8.62(\mathrm{dd}, J=8.0,1.5 \mathrm{~Hz}, 1 \mathrm{H}), 7.97-7.81(\mathrm{~m}, 2 \mathrm{H}), 7.75(\mathrm{~d}, J=8.6 \mathrm{~Hz}, 1 \mathrm{H})$, $7.64(\mathrm{dqd}, J=8.4,6.9,1.5 \mathrm{~Hz}, 2 \mathrm{H}), 2.45(\mathrm{~d}, J=1.0 \mathrm{~Hz}, 3 \mathrm{H}), 2.35(\mathrm{~d}, J=1.0 \mathrm{~Hz}, 3 \mathrm{H}) ;{ }^{13} \mathrm{C}-\mathrm{NMR}(101 \mathrm{MHz}$, Chloroform- $d$ ) $\delta 158.85,156.63,150.72,148.77,133.86,127.98,127.77,127.19,124.53,123.46,122.48$, 116.99, 114.04, 111.08, 108.35, 11.59, 8.62; IR (KBr) v $\left(\mathrm{cm}^{-1}\right)$ 2925, 1724, 1632, 1621, 1601, 1593, 1458; HR-MS (ESI): $m / z$ calcd for $\mathrm{C}_{17} \mathrm{H}_{12} \mathrm{O}_{3}\left([\mathrm{M}+\mathrm{H}]^{+}\right)$265.0865, found 265.0859 .

2-Acetyl-3-methyl-4H-benzo[g]furo[3,2-c]chromen-4-one (5k): yellow solid, m.p. 248.9-249.4 ${ }^{\circ} \mathrm{C} ;{ }^{1} \mathrm{H}-\mathrm{NMR}$ (400 MHz, Chloroform- $d$ ) $\delta 8.66-8.55(\mathrm{~m}, 1 \mathrm{H}), 8.00-7.88(\mathrm{~m}, 2 \mathrm{H}), 7.81(\mathrm{~d}, J=8.6 \mathrm{~Hz}, 1 \mathrm{H}), 7.73-7.66$ (m, 2H), $2.78(\mathrm{~s}, 3 \mathrm{H}), 2.67$ (s, 3H); ${ }^{13} \mathrm{C}-\mathrm{NMR}(101 \mathrm{MHz}$, Chloroform-d) $\delta 188.65,158.20,157.68,151.01$, 149.04, 134.95, 129.63, 128.96, 128.12, 127.66, 125.09, 123.22, 122.70, 116.98, 111.56, 107.31, 27.64, 10.33; IR $(\mathrm{KBr}) \vee\left(\mathrm{cm}^{-1}\right) 2916,1737,1673,1614,1597,1556,1495 ;$ HR-MS (ESI): $m / z$ calcd for $\mathrm{C}_{18} \mathrm{H}_{12} \mathrm{O}_{4}$ $\left([\mathrm{M}+\mathrm{H}]^{+}\right) 293.0814$ found 293.0807 .

\subsubsection{General Procedure for the Synthesis of Target Compounds 6 and 7 (Scheme 1)}

A mixture of substituted furocoumarin $5(10 \mathrm{mmol})$ and $5 \% \mathrm{KOH}$ solution $(45 \mathrm{~mL})$ was stirred until completely dissolved, then dimethylsulfate $(1.0 \mathrm{~mL}, 10 \mathrm{mmol})$ was added in a single portion via syringe. The mixture was refluxed for about $10 \mathrm{~h}$ until full conversion (monitored by TLC), then cooled to room temperature and acidified to $\mathrm{pH}=4-5$ with $5 \% \mathrm{HCl}$ solution, then extracted with EtOAc three times $(3 \times 50 \mathrm{~mL})$, the extract was dried over anhydrous $\mathrm{Na}_{2} \mathrm{SO}_{4}$, and concentrated under reduced pressure. The crude product was purified by recrystallized from acetone to give the target compound 6 . 
Compound 6 ( $5 \mathrm{mmol}$ ) was dissolved in $20 \mathrm{~mL} \mathrm{CH}_{3} \mathrm{OH}$ along with $\mathrm{SOCl}_{2}$ (30 mmol), the mixture was stirred at room temperature for about $8 \mathrm{~h}$. After completion of the reaction, the mixture was concentrated at reduced pressure, and then $50 \mathrm{~mL}$ of water was added, and extracted with EtOAc $(3 \times 30 \mathrm{~mL})$ and washed with saturated $\mathrm{NaHCO}_{3}$ solution $(30 \mathrm{~mL})$, washed with water $(30 \mathrm{~mL})$, the organic phase was dried over anhydrous $\mathrm{Na}_{2} \mathrm{SO}_{4}$, and concentrated under reduced pressure to afford the target compound 7.

The reaction yields were not optimized, and the structures of target compounds 6 and 7 are summarized in Table 4.

Table 4. The yields and structures of target compounds 6 and 7.

\begin{tabular}{cccccccc}
\hline Compound & $\mathbf{R}_{\mathbf{1}}$ & $\mathbf{R}_{\mathbf{2}}$ & Yield & Compound & $\mathbf{R}_{\mathbf{1}}$ & $\mathbf{R}_{\mathbf{2}}$ & Yield \\
\hline $\mathbf{6 a}$ & $\mathrm{H}$ & $\mathrm{H}$ & $65 \%$ & $\mathbf{7 a}$ & $\mathrm{H}$ & $\mathrm{H}$ & $75 \%$ \\
$\mathbf{6 b}$ & $\mathrm{H}$ & $\mathrm{Me}$ & $55 \%$ & $\mathbf{7 b}$ & $\mathrm{H}$ & $\mathrm{Me}$ & $65 \%$ \\
$\mathbf{6 c}$ & $\mathrm{H}$ & $\mathrm{Ac}$ & $55 \%$ & $\mathbf{7 c}$ & $\mathrm{H}$ & $\mathrm{Ac}$ & $68 \%$ \\
$\mathbf{6 d}$ & $4-\mathrm{OMe}$ & $\mathrm{H}$ & $60 \%$ & $\mathbf{7 d}$ & $4-\mathrm{OMe}$ & $\mathrm{H}$ & $74 \%$ \\
$\mathbf{6 e}$ & $4-\mathrm{OMe}$ & $\mathrm{Me}$ & $56 \%$ & $\mathbf{7 e}$ & $4-\mathrm{OMe}$ & $\mathrm{Me}$ & $71 \%$ \\
$\mathbf{6 f}$ & $4-\mathrm{OMe}$ & $\mathrm{Ac}$ & $51 \%$ & $\mathbf{7 f}$ & $4-\mathrm{OMe}$ & $\mathrm{Ac}$ & $73 \%$ \\
$\mathbf{6 g}$ & $5-\mathrm{Me}$ & $\mathrm{H}$ & $71 \%$ & $\mathbf{7 g}$ & $5-\mathrm{Me}$ & $\mathrm{H}$ & $69 \%$ \\
$\mathbf{6 h}$ & $5-\mathrm{Me}$ & $\mathrm{Me}$ & $50 \%$ & $\mathbf{7 h}$ & $5-\mathrm{Me}$ & $\mathrm{Me}$ & $62 \%$ \\
$\mathbf{6 i}$ & $4,5-(\mathrm{CH})_{4}$ & $\mathrm{H}$ & $48 \%$ & $\mathbf{7 i}$ & $4,5-(\mathrm{CH})_{4}$ & $\mathrm{H}$ & $58 \%$ \\
\hline
\end{tabular}

2-(2-Methoxyphenyl)-4-methylfuran-3-carboxylic acid (6a): yellow solid, m.p. $134.0-134.2{ }^{\circ} \mathrm{C} ;{ }^{1} \mathrm{H}-\mathrm{NMR}$ $\left(400 \mathrm{MHz}\right.$, Chloroform- $\left.d_{3}\right) \delta 7.43(\mathrm{ddd}, J=15.5,7.6,1.7 \mathrm{~Hz}, 2 \mathrm{H}), 7.30(\mathrm{~d}, J=1.3 \mathrm{~Hz}, 1 \mathrm{H}), 7.04(\mathrm{td}, J=7.5$, $1.0 \mathrm{~Hz}, 1 \mathrm{H}), 6.98(\mathrm{~d}, J=8.3 \mathrm{~Hz}, 1 \mathrm{H}), 3.82(\mathrm{~s}, 3 \mathrm{H}), 2.24(\mathrm{~s}, 3 \mathrm{H})$; IR (KBr) v (cm $\left.{ }^{-1}\right)$ 3072, 2965, 1680, 1616, 1580, 1557, 1464; HR-MS (ESI): $m / z$ calcd for $\mathrm{C}_{13} \mathrm{H}_{12} \mathrm{O}_{4}\left([\mathrm{M}+\mathrm{H}]^{+}\right)$233.0814, found 233.0807.

2-(2-Methoxyphenyl)-4,5-dimethylfuran-3-carboxylic acid (6b): light yellow solid, m.p. 197.0-197.8 ${ }^{\circ} \mathrm{C}$; ${ }^{1} \mathrm{H}-\mathrm{NMR}\left(400 \mathrm{MHz}\right.$, Acetone- $\left.d_{6}\right) \delta 7.40(\mathrm{td}, J=7.4,1.2 \mathrm{~Hz}, 2 \mathrm{H}), 7.07(\mathrm{~d}, J=8.5 \mathrm{~Hz}, 1 \mathrm{H}), 7.01(\mathrm{t}, J=7.5 \mathrm{~Hz}$, $1 \mathrm{H}), 3.79(\mathrm{~s}, 3 \mathrm{H}), 2.26$ (s, 3H), $2.12(\mathrm{~s}, 3 \mathrm{H}) ;{ }^{13} \mathrm{C}-\mathrm{NMR}\left(101 \mathrm{MHz}, \mathrm{DMSO}-d_{6}\right) \delta 165.70,157.25,151.44,147.51$, $130.84,130.70,120.43,120.37,117.49,115.47,111.89,55.72,11.50,9.81$; IR (KBr) $\vee\left(\mathrm{cm}^{-1}\right) 3050,2983$, 1683, 1607, 1580, 1565, 1484; HR-MS (ESI): $m / z$ calcd for $\mathrm{C}_{14} \mathrm{H}_{14} \mathrm{O}_{4}\left([\mathrm{M}+\mathrm{H}]^{+}\right)$247.0970, found 247.0962.

5-Acetyl-2-(2-methoxyphenyl)-4-methylfuran-3-carboxylic acid (6c): white solid, m.p. $212.6-213.6{ }^{\circ} \mathrm{C}$; ${ }^{1} \mathrm{H}-\mathrm{NMR}\left(400 \mathrm{MHz}\right.$, Acetone- $\left.d_{6}\right) \delta 7.61(\mathrm{dd}, J=7.5,1.7 \mathrm{~Hz}, 1 \mathrm{H}), 7.55-7.47(\mathrm{~m}, 1 \mathrm{H}), 7.19-7.06(\mathrm{~m}, 2 \mathrm{H})$, $3.84(\mathrm{~s}, 3 \mathrm{H}), 2.55(\mathrm{~s}, 3 \mathrm{H}), 2.48(\mathrm{~s}, 3 \mathrm{H}) ;{ }^{13} \mathrm{C}-\mathrm{NMR}\left(101 \mathrm{MHz}, \mathrm{DMSO}-d_{6}\right) \delta 188.77,164.83,157.53,154.38$, $147.53,132.18,130.43,130.13,120.75,120.15,118.96,112.25,55.83,27.76,10.84 ; \mathrm{IR}(\mathrm{KBr}) \vee\left(\mathrm{cm}^{-1}\right) 3052$, 2937, 1703, 1667, 1606, 1581, 1536, 1494; HR-MS (ESI): $m / z$ calcd for $\mathrm{C}_{15} \mathrm{H}_{14} \mathrm{O}_{5}\left([\mathrm{M}+\mathrm{H}]^{+}\right)$275.0919, found 275.0912 .

2-(2,4-Dimethoxyphenyl)-4-methylfuran-3-carboxylic acid (6d): light yellow solid, m.p. $140.9-141.2{ }^{\circ} \mathrm{C}$; ${ }^{1} \mathrm{H}-\mathrm{NMR}\left(400 \mathrm{MHz}\right.$, Chloroform- $\left.d_{3}\right) \delta 7.38(\mathrm{~d}, J=8.4 \mathrm{~Hz}, 1 \mathrm{H}), 7.28-7.25(\mathrm{~m}, 1 \mathrm{H}), 6.57(\mathrm{dd}, J=8.5,2.3 \mathrm{~Hz}$, $1 \mathrm{H}), 6.53(\mathrm{~d}, J=2.3 \mathrm{~Hz}, 1 \mathrm{H}), 3.87(\mathrm{~s}, 3 \mathrm{H}), 3.80(\mathrm{~s}, 3 \mathrm{H}), 2.23(\mathrm{~s}, 3 \mathrm{H})$; IR $(\mathrm{KBr}) v\left(\mathrm{~cm}^{-1}\right) 3110,2962,1678$, 1619, 1597, 1578, 1549, 1481; HR-MS (ESI): $m / z$ calcd for $\mathrm{C}_{14} \mathrm{H}_{14} \mathrm{O}_{5}\left([\mathrm{M}+\mathrm{H}]^{+}\right)$263.0919, found 263.0911.

2-(2,4-Dimethoxyphenyl)-4,5-dimethylfuran-3-carboxylic acid (6e): light yellow solid, m.p. 156.9-158.3 ${ }^{\circ} \mathrm{C}$; ${ }^{1} \mathrm{H}-\mathrm{NMR}\left(400 \mathrm{MHz}\right.$, Acetone- $\left.d_{6}\right) \delta 7.31(\mathrm{~d}, J=8.4 \mathrm{~Hz}, 1 \mathrm{H}), 6.64-6.55(\mathrm{~m}, 2 \mathrm{H}), 3.86(\mathrm{~s}, 3 \mathrm{H}), 3.78(\mathrm{~s}, 3 \mathrm{H})$, $2.24(\mathrm{~s}, 3 \mathrm{H}), 2.11(\mathrm{~s}, 3 \mathrm{H}) ;{ }^{13} \mathrm{C}-\mathrm{NMR}\left(101 \mathrm{MHz}, \mathrm{DMSO}-d_{6}\right) \delta 165.79,161.72,158.57,151.95,147.00,131.63$, 116.75, 115.37, 113.18, 105.16, 98.89, 55.80, 55.77, 11.48, 9.89; IR (KBr) v (cm $\left.{ }^{-1}\right) 3076,2961,1690,1615$, 1579, 1445; HR-MS (ESI): $m / z$ calcd for $\mathrm{C}_{15} \mathrm{H}_{16} \mathrm{O}_{5}\left([\mathrm{M}+\mathrm{H}]^{+}\right)$277.1076, found 277.1068.

5-Acetyl-2-(2,4-dimethoxyphenyl)-4-methylfuran-3-carboxylic acid (6f): orange solid, m.p. 170.0-171.3 ${ }^{\circ} \mathrm{C}$; ${ }^{1} \mathrm{H}-\mathrm{NMR}\left(400 \mathrm{MHz}, \mathrm{DMSO}-d_{6}\right) \delta 7.46(\mathrm{~d}, J=8.4 \mathrm{~Hz}, 1 \mathrm{H}), 6.71-6.63(\mathrm{~m}, 2 \mathrm{H}), 3.84(\mathrm{~s}, 3 \mathrm{H}), 3.76(\mathrm{~s}, 3 \mathrm{H})$, 2.45 (s, 3H), $2.43(\mathrm{~s}, 3 \mathrm{H}) ;{ }^{13} \mathrm{C}-\mathrm{NMR}\left(101 \mathrm{MHz}, \mathrm{DMSO}-d_{6}\right) \delta 188.62,165.01,162.78,158.92,154.72,147.15$, 
131.37, 130.30, 119.37, 111.65, 105.89, 99.07, 55.95, 55.89, 27.71, 10.88; IR (KBr) v (cm $\left.{ }^{-1}\right) 3071,2930,1662$, 1614, 1580, 1540, 1450; HR-MS (ESI): $m / z$ calcd for $\mathrm{C}_{16} \mathrm{H}_{16} \mathrm{O}_{6}\left([\mathrm{M}+\mathrm{H}]^{+}\right)$305.1025, found 305.1018.

2-(2-Methoxy-5-methylphenyl)-4-methylfuran-3-carboxylic acid (6g): yellow solid, m.p. 143.7-144.2 ${ }^{\circ} \mathrm{C}$; ${ }^{1} \mathrm{H}-\mathrm{NMR}(400 \mathrm{MHz}$, Chloroform- $d) \delta 7.29(\mathrm{~d}, J=1.2 \mathrm{~Hz}, 1 \mathrm{H}), 7.26(\mathrm{~d}, J=2.2 \mathrm{~Hz}, 1 \mathrm{H}), 7.24-7.19(\mathrm{~m}, 1 \mathrm{H})$, $6.87(\mathrm{~d}, J=8.4 \mathrm{~Hz}, 1 \mathrm{H}), 3.80(\mathrm{~s}, 3 \mathrm{H}), 2.34(\mathrm{~s}, 3 \mathrm{H}), 2.23(\mathrm{~s}, 3 \mathrm{H}) ;{ }^{13} \mathrm{C}-\mathrm{NMR}\left(101 \mathrm{MHz}, \mathrm{DMSO}-d_{6}\right) \delta 165.52$, 155.27, 154.14, 139.98, 131.38, 131.03, 129.11, 121.41, 120.01, 117.01, 111.90, 55.77, 20.36, 9.93; IR (KBr) v $\left(\mathrm{cm}^{-1}\right)$ 3078, 2998, 1673, 1552, 1502, 1451; HR-MS (ESI): $\mathrm{m} / z$ calcd for $\mathrm{C}_{14} \mathrm{H}_{14} \mathrm{O}_{4}\left([\mathrm{M}+\mathrm{H}]^{+}\right)$247.0970, found 247.0963 .

2-(2-Methoxy-5-methylphenyl)-4,5-dimethylfuran-3-carboxylic acid (6h): yellow solid, m.p. $213.8-214.5^{\circ} \mathrm{C}$; ${ }^{1} \mathrm{H}-\mathrm{NMR}\left(400 \mathrm{MHz}\right.$, Acetone- $\left.d_{6}\right) \delta 7.44-7.39(\mathrm{~m}, 1 \mathrm{H}), 7.34-7.28(\mathrm{~m}, 1 \mathrm{H}), 7.04(\mathrm{~d}, J=8.5 \mathrm{~Hz}, 1 \mathrm{H}), 3.80$ $(\mathrm{s}, 3 \mathrm{H}), 2.54(\mathrm{~s}, 3 \mathrm{H}), 2.48(\mathrm{~s}, 3 \mathrm{H}), 2.34(\mathrm{~s}, 3 \mathrm{H}),{ }^{13} \mathrm{C}-\mathrm{NMR}\left(101 \mathrm{MHz}, \mathrm{DMSO}-d_{6}\right) \delta 188.72,164.85,155.52$, 154.42, 147.47, 132.47, 130.50, 130.14, 129.56, 120.14, 118.69, 112.20, 55.84, 27.78, 20.37, 10.84; IR (KBr) v $\left(\mathrm{cm}^{-1}\right)$ 3062, 2997, 1664, 1619, 1577, 1536, 1501, 1456; HR-MS (ESI): $\mathrm{m} / z$ calcd for $\mathrm{C}_{16} \mathrm{H}_{16} \mathrm{O}_{5}\left([\mathrm{M}+\mathrm{H}]^{+}\right)$ 289.1076, found 289.1069 .

2-(3-Methoxynaphthalen-2-yl)-4-methylfuran-3-carboxylic acid (6i): orange solid, m.p. $137.9-138.6{ }^{\circ} \mathrm{C}$; ${ }^{1} \mathrm{H}-\mathrm{NMR}\left(300 \mathrm{MHz}\right.$, DMSO- $\left.d_{6}\right) \delta 8.16-8.08(\mathrm{~m}, 1 \mathrm{H}), 8.00-7.93(\mathrm{~m}, 1 \mathrm{H}), 7.73-7.66(\mathrm{~m}, 2 \mathrm{H}), 7.64-7.55$ $(\mathrm{m}, 2 \mathrm{H}), 7.46(\mathrm{~d}, J=8.5 \mathrm{~Hz}, 1 \mathrm{H}), 3.63(\mathrm{~s}, 3 \mathrm{H}), 2.17(\mathrm{~s}, 3 \mathrm{H}) ; \mathrm{IR}(\mathrm{KBr}) \vee\left(\mathrm{cm}^{-1}\right) 3059,2987,1678,1608,1594$, 1556, 1501, 1471; HR-MS (ESI): $m / z$ calcd for $\mathrm{C}_{17} \mathrm{H}_{14} \mathrm{O}_{4}\left([\mathrm{M}+\mathrm{H}]^{+}\right)$283.0970, found 283.0963.

Methyl 2-(2-methoxyphenyl)-4-methylfuran-3-carboxylate (7a): yellow oil, ${ }^{1} \mathrm{H}-\mathrm{NMR}$ (400 MHz, DMSO- $d_{6}$ ) $\delta 7.61(\mathrm{~d}, J=1.4 \mathrm{~Hz}, 1 \mathrm{H}), 7.11(\mathrm{~d}, J=8.4 \mathrm{~Hz}, 1 \mathrm{H}), 7.03(\mathrm{td}, J=7.5,1.0 \mathrm{~Hz}, 2 \mathrm{H}), 3.73(\mathrm{~s}, 3 \mathrm{H}), 3.61(\mathrm{~s}, 3 \mathrm{H})$, $2.11(\mathrm{~s}, 3 \mathrm{H})$; IR (KBr) $v\left(\mathrm{~cm}^{-1}\right)$ 2950, 1770, 1713, 1598, 1582, 1552, 1493; HR-MS (ESI): $\mathrm{m} / \mathrm{z}$ calcd for $\mathrm{C}_{14} \mathrm{H}_{14} \mathrm{O}_{4}\left([\mathrm{M}+\mathrm{H}]^{+}\right)$247.0970, found 247.0963.

Methyl 2-(2-methoxyphenyl)-4,5-dimethylfuran-3-carboxylate (7b): yellow solid, m.p. $55.5-56.2{ }^{\circ} \mathrm{C}$; ${ }^{1} \mathrm{H}-\mathrm{NMR}\left(400 \mathrm{MHz}\right.$, DMSO- $\left.d_{6}\right) \delta 7.52-7.33(\mathrm{~m}, 2 \mathrm{H}), 7.09(\mathrm{dd}, J=8.4,1.0 \mathrm{~Hz}, 1 \mathrm{H}), 7.01(\mathrm{td}, J=7.5,1.0 \mathrm{~Hz}$, $1 \mathrm{H}), 3.72(\mathrm{~s}, 3 \mathrm{H}), 3.59(\mathrm{~s}, 3 \mathrm{H}), 2.25(\mathrm{~s}, 3 \mathrm{H}), 2.04(\mathrm{~s}, 3 \mathrm{H}) .{ }^{13} \mathrm{C}-\mathrm{NMR}\left(101 \mathrm{MHz}, \mathrm{DMSO}-d_{6}\right) \delta 164.78,156.76$, 151.02, 147.86, 130.97, 130.11, 120.54, 119.88, 116.86, 115.34, 111.82, 55.82, 51.48, 11.49, 9.53; IR (KBr) v $\left(\mathrm{cm}^{-1}\right) 3047,2924,1710,1633,1602,1581,1560,1495$; HR-MS (ESI): $m / z$ calcd for $\mathrm{C}_{15} \mathrm{H}_{16} \mathrm{O}_{4}\left([\mathrm{M}+\mathrm{H}]^{+}\right)$ 261.1127, found 261.1121.

Methyl 5-acetyl-2-(2-methoxyphenyl)-4-methylfuran-3-carboxylate (7c): white solid, m.p. $61.4-62.2{ }^{\circ} \mathrm{C}$; ${ }^{1} \mathrm{H}-\mathrm{NMR}\left(300 \mathrm{MHz}, \mathrm{DMSO}-d_{6}\right) \delta 7.58(\mathrm{dd}, J=7.6,1.7 \mathrm{~Hz}, 1 \mathrm{H}), 7.50(\mathrm{ddd}, J=8.4,7.4,1.8 \mathrm{~Hz}, 1 \mathrm{H})$, 7.19-7.05 (m, 2H), $3.74(\mathrm{~s}, 3 \mathrm{H}), 3.64(\mathrm{~s}, 3 \mathrm{H}), 2.45(\mathrm{~s}, 3 \mathrm{H}), 2.43(\mathrm{~s}, 3 \mathrm{H}) .{ }^{13} \mathrm{C}-\mathrm{NMR}\left(101 \mathrm{MHz}, \mathrm{DMSO}-d_{6}\right)$ $\delta 188.78,163.89,157.13,153.99,147.56,132.44,130.13,129.82,120.94,119.25,118.40,112.14,56.00,52.05$, 27.77, 10.62; IR (KBr) $v\left(\mathrm{~cm}^{-1}\right)$ 2948, 1725, 1665, 1610, 1584, 1534, 1492; HR-MS (ESI): $m / z$ calcd for $\mathrm{C}_{16} \mathrm{H}_{16} \mathrm{O}_{5}\left([\mathrm{M}+\mathrm{H}]^{+}\right)$289.1076, found 289.1068.

Methyl 2-(2,4-dimethoxyphenyl)-4-methylfuran-3-carboxylate (7d): yellow oil; ${ }^{1} \mathrm{H}-\mathrm{NMR}(400 \mathrm{MHz}$, DMSO- $\left.d_{6}\right) \delta 7.55(\mathrm{~d}, J=1.5 \mathrm{~Hz}, 1 \mathrm{H}), 7.31(\mathrm{~d}, J=8.4 \mathrm{~Hz}, 1 \mathrm{H}), 6.77-6.54(\mathrm{~m}, 2 \mathrm{H}), 3.82(\mathrm{~s}, 3 \mathrm{H}), 3.72$ (s, 3H), $3.61(\mathrm{~s}, 3 \mathrm{H}), 2.10(\mathrm{~s}, 3 \mathrm{H})$; IR (KBr) v $\left(\mathrm{cm}^{-1}\right)$ 3052, 2948, 1711, 1618, 1578, 1503, 1455; HR-MS (ESI): $m / z$ calcd for $\mathrm{C}_{15} \mathrm{H}_{16} \mathrm{O}_{5}\left([\mathrm{M}+\mathrm{H}]^{+}\right)$277.1076, found 277.1069.

Methyl 2-(2,4-dimethoxyphenyl)-4,5-dimethylfuran-3-carboxylate (7e): yellow solid, m.p. 71.6-73.2 ${ }^{\circ} \mathrm{C}$; ${ }^{1} \mathrm{H}-\mathrm{NMR}\left(300 \mathrm{MHz}, \mathrm{DMSO}-d_{6}\right) \delta 7.53(\mathrm{~d}, J=8.6 \mathrm{~Hz}, 1 \mathrm{H}), 6.61(\mathrm{~d}, J=2.4 \mathrm{~Hz}, 1 \mathrm{H}), 6.56(\mathrm{dd}, J=8.6$, $2.4 \mathrm{~Hz}, 1 \mathrm{H}), 3.86(\mathrm{~s}, 3 \mathrm{H}), 3.77(\mathrm{~s}, 3 \mathrm{H}), 3.68(\mathrm{~s}, 3 \mathrm{H}) 2.21(\mathrm{~s}, 3 \mathrm{H}), 1.91(\mathrm{~s}, 3 \mathrm{H}) . \mathrm{IR}(\mathrm{KBr}) v\left(\mathrm{~cm}^{-1}\right)$ 3068, 2922, 1714, 1612, 1582, 1498; HR-MS (ESI): $m / z$ calcd for $\mathrm{C}_{16} \mathrm{H}_{18} \mathrm{O}_{5}\left([\mathrm{M}+\mathrm{H}]^{+}\right)$291.1232, found 291.1226.

Methyl 5-acetyl-2-(2,4-dimethoxyphenyl)-4-methylfuran-3-carboxylate (7f): yellow solid, m.p. 120.2-12.4 ${ }^{\circ} \mathrm{C}$; ${ }^{1} \mathrm{H}-\mathrm{NMR}\left(400 \mathrm{MHz}\right.$, DMSO- $\left.d_{6}\right) \delta 7.53(\mathrm{~d}, J=9.1 \mathrm{~Hz}, 1 \mathrm{H}), 6.69(\mathrm{dd}, J=5.2,2.3 \mathrm{~Hz}, 2 \mathrm{H}), 3.85(\mathrm{~s}, 3 \mathrm{H})$, $3.76(\mathrm{~s}, 3 \mathrm{H}), 3.67(\mathrm{~s}, 3 \mathrm{H}), 2.45(\mathrm{~s}, 3 \mathrm{H}), 2.43(\mathrm{~s}, 3 \mathrm{H}) .{ }^{13} \mathrm{C}-\mathrm{NMR}\left(101 \mathrm{MHz}, \mathrm{DMSO}-d_{6}\right) \delta 188.61,164.08$, $162.95,158.56,154.37,147.16,131.13,130.01,118.35$, 111.17, 106.06, 99.00, 56.09, 56.00, 51.97, 27.73, 
10.66; IR $(\mathrm{KBr}) \vee\left(\mathrm{cm}^{-1}\right) 3020,2918,1708,1662,1615,1582,1439$; HR-MS (ESI): $m / z$ calcd for $\mathrm{C}_{17} \mathrm{H}_{18} \mathrm{O}_{6}$ $\left([\mathrm{M}+\mathrm{H}]^{+}\right) 319.1182$, found 319.1175 .

Methyl 2-(2-methoxy-5-methylphenyl)-4-methylfuran-3-carboxylate (7g): yellow oil; ${ }^{1} \mathrm{H}-\mathrm{NMR}(300 \mathrm{MHz}$, DMSO- $\left.d_{6}\right) \delta 7.57(\mathrm{q}, J=1.2 \mathrm{~Hz}, 1 \mathrm{H}), 7.24-7.16(\mathrm{~m}, 2 \mathrm{H}), 6.97(\mathrm{~d}, J=8.3 \mathrm{~Hz}, 1 \mathrm{H}), 3.67(\mathrm{~s}, 3 \mathrm{H}), 3.59(\mathrm{~s}, 3 \mathrm{H})$, $2.26(\mathrm{~s}, 3 \mathrm{H}), 2.08(\mathrm{~s}, 3 \mathrm{H})$; IR (KBr) $\vee\left(\mathrm{cm}^{-1}\right)$ 2950, 1707, 1617, 1553, 1498, 1438; HR-MS (ESI): $m / z$ calcd for $\mathrm{C}_{15} \mathrm{H}_{16} \mathrm{O}_{4}\left([\mathrm{M}+\mathrm{H}]^{+}\right)$261.1127, found 261.1122.

Methyl 2-(2-methoxy-5-methylphenyl)-4,5-dimethylfuran-3-carboxylate (7h): yellow solid, m.p. 117.8-118.1 ${ }^{\circ} \mathrm{C}$; ${ }^{1} \mathrm{H}-\mathrm{NMR}\left(400 \mathrm{MHz}\right.$, DMSO- $\left.d_{6}\right) \delta 7.40(\mathrm{~d}, J=2.2 \mathrm{~Hz}, 1 \mathrm{H}), 7.32(\mathrm{dd}, J=8.6,2.3 \mathrm{~Hz}, 1 \mathrm{H}), 7.05(\mathrm{~d}, J=8.5 \mathrm{~Hz}$, $1 \mathrm{H}), 3.72(\mathrm{~s}, 3 \mathrm{H}), 3.65(\mathrm{~s}, 3 \mathrm{H}), 2.47(\mathrm{~s}, 3 \mathrm{H}), 2.44(\mathrm{~s}, 3 \mathrm{H}), 2.32(\mathrm{~s}, 3 \mathrm{H}) ;{ }^{13} \mathrm{C}-\mathrm{NMR}\left(101 \mathrm{MHz}, \mathrm{DMSO}-d_{6}\right) \delta$ $188.73,163.92,155.12,154.04,147.51,132.76,130.20,129.84,129.79,119.24,118.10,112.05,56.00,52.01$, 27.80, 20.37, 10.62; IR (KBr) $v\left(\mathrm{~cm}^{-1}\right)$ 3049, 2917, 1708, 1665, 1584, 1505, 1440; HR-MS (ESI): $\mathrm{m} / z$ calcd for $\mathrm{C}_{17} \mathrm{H}_{18} \mathrm{O}_{5}\left([\mathrm{M}+\mathrm{H}]^{+}\right)$303.1232, found 303.1226.

Methyl 2-(3-methoxynaphthalen-2-yl)-4-methylfuran-3-carboxylate (7i): yellow oil; ${ }^{1} \mathrm{H}-\mathrm{NMR}(300 \mathrm{MHz}$, DMSO- $\left.d_{6}\right) \delta 8.13(\mathrm{ddd}, J=6.2,2.3,1.4 \mathrm{~Hz}, 1 \mathrm{H}), 7.97(\mathrm{dt}, J=5.2,3.1 \mathrm{~Hz}, 1 \mathrm{H}), 7.77-7.70(\mathrm{~m}, 2 \mathrm{H}), 7.65-7.57$ $(\mathrm{m}, 2 \mathrm{H}), 7.50(\mathrm{~d}, J=8.5 \mathrm{~Hz}, 1 \mathrm{H}), 3.60(\mathrm{~s}, 3 \mathrm{H}), 3.59(\mathrm{~s}, 3 \mathrm{H}), 2.16(\mathrm{~s}, 3 \mathrm{H}) . \mathrm{IR}(\mathrm{KBr}) \vee\left(\mathrm{cm}^{-1}\right)$ 2922, 1727, $1618,1579,1493$; HR-MS (ESI): $m / z$ calcd for $\mathrm{C}_{18} \mathrm{H}_{16} \mathrm{O}_{4}\left([\mathrm{M}+\mathrm{H}]^{+}\right)$297.1127, found 297.1120.

\subsection{Biological Assays}

Many experimental protocols for antifungal tests are reported in the literature [22,23].In this study, the antifungal activities of all the synthesized target compounds were carried out at the concentration of $50 \mu \mathrm{M}$ using mycelia growth inhibitory rate methods, with Azoxystrobin used as the positive control. For the detailed procedure of experimental methods for the antifungal activity, refer to the paper from Department of Plant Pathology, Nanjing Agriculture University [24]. The assay of antifungal activity toward Botrytis cinerea, Alternariasolani, Gibberellazeae, Rhizoctorziasolani, Cucumber anthrax and Alternariamali was carried out on $100 \mathrm{~mm} \times 15 \mathrm{~mm}$ Petri plates each contained $10 \mathrm{~mL}$ potato dextrose agar, under sterile conditions, on a clean bench in a sterile room. Sterile blank paper disks $(0.65 \mathrm{~cm}$ in diameter) were placed at a distance $2.5 \mathrm{~cm}$ away from the rim of the mycelial colony. The plates were sealed with parafilm, and incubated at $25^{\circ} \mathrm{C}$ until mycelial growth had enveloped disks containing the control and had formed crescents of inhibition around disks containing samples with antifungal activity. When the mycelia colony of the control had grown to almost fill the plate, the area of the mycelia colony was measured, and the inhibition of fungal growth in the other plates was determined by calculating the percent reduction in the area of the mycelia colony. The resulting data were collated for each compound, and averages across replicates were used to make a judgment of the overall activity level of the compound.

The antifungal data listed in Table 1 are the screening results of all the compounds against Botrytis cinerea, Alternaria solani, Gibberella zeae, Rhizoctorzia solani, Cucumber anthrax and Alternaria mali, which are the most common phytopathogenic fungi in China.

\section{Conclusions}

In summary, aiming to discover novel Osthole analogs with improved antifungal activity, we have designed and synthesized two series of coumarin ring-opening derivatives through hydrolysis and methylation. Biological testing data showed that some target compounds displayed an altered pattern of biological activity, and compounds $6 \mathrm{~b}, 6 \mathrm{e}, \mathbf{6 g}, \mathbf{6 i}, 7 \mathrm{~b}$ and $7 \mathrm{c}$ were identified as the most active ones. The $\mathrm{EC}_{50}$ values of these compounds together with Azoxystrobin were further tested. Compared to Azoxystrobin $(0.0884 \mu \mathrm{M})$, compound $\mathbf{6 b}(0.0544 \mu \mathrm{M})$ and $\mathbf{6 e}(0.0823 \mu \mathrm{M})$ displayed improved activity against Botrytis cinerea. Further structural optimization of coumarin ring-opening derivatives is well underway, with the aim to improve their levels of antifungal activity. 
Acknowledgments: The project was supported by the National Natural Science Foundation of China (21272116) and the Fundamental Research Funds for the Central Universities (KYTZ201604).

Author Contributions: Ming-Zhi Zhang and Wei-Hua Zhang conceived and designed the experiments; Yu Zhang and Jia-Qun Wang performed the experiments; Ming-Zhi Zhang analyzed the data and wrote the paper.

Conflicts of Interest: The authors declare no conflict of interest.

\section{References}

1. Bovicelli, P.; Sanetti, A.; Bernini, R.; Lupattelli, P. Oxyfunctionalisation of activated methylenes by dimethyldioxirane: An easy conversion of isochromans into isocoumarins. Tetrahedron 1997, 53, 9755-9760. [CrossRef]

2. Bovicelli, P.; Lupattelli, P.; Crescenzi, B.; Sanetti, A.; Bernini, R. Oxidation of 3-arylisochromans by dimethyldioxirane. An easy route to substituted 3-arylisocoumarins. Tetrahedron 1999, 55, 14719-14728.

3. Tsay, S.C.; Lin, S.Y.; Huang, W.C.; Hsu, M.H.; Hwang, K.C.; Lin, C.C.; Horng, J.C.; Chen, I.C.; Hwu, J.R.; Shieh, F.K.; et al. Synthesis and Structure-activity relationships of imidazole-coumarin conjugates against hepatitis C virus. Molecules 2016, 21, 228. [CrossRef] [PubMed]

4. Tian, Y.; Liang, Z.; Xu, H.; Mou, Y.; Guo, C. Design, synthesis and cytotoxicity of novel dihydroartemisinin-coumarin hybrids via click chemistry. Molecules 2016, 21, 758. [CrossRef] [PubMed]

5. Medina, F.G.; Marrero, J.G.; Macias-Alonso, M.; Gonzalez, M.C.; Cordova-Guerrero, I.; Teissier Garcia, A.G.; Osegueda-Robles, S. Coumarin heterocyclic derivatives: Chemical synthesis and biological activity. Nat. Prod. Rep. 2015, 32, 1472-1507. [CrossRef] [PubMed]

6. Emami, S.; Dadashpour, S. Current developments of coumarin-based anti-cancer agents in medicinal chemistry. Eur. J. Med. Chem. 2015, 102, 611-630. [CrossRef] [PubMed]

7. Vogl, S.; Zehl, M.; Picker, P.; Urban, E.; Wawrosch, C.; Reznicek, G.; Saukel, J.; Kopp, B. Identification and quantification of coumarins in Peucedanum ostruthium (L.) Koch by HPLC-DAD and HPLC-DAD-MS. J. Agric. Food Chem. 2011, 59, 4371-4377. [CrossRef] [PubMed]

8. Wei, Y.; Zhang, T.; Ito, Y. Preparative isolation of osthol and xanthotoxol from Common Cnidium Fruit (Chinese traditional herb) using stepwise elution by high-speed counter-current chromatography. J. Chromatogr. A 2004, 1033, 373-377. [CrossRef] [PubMed]

9. Shi, Z.; Wang, F.; Zhou, W.; Zhang, P.; Fan, Y.J. Application of osthol induces a resistance response against powdery mildew in pumpkin leaves. Int. J. Mol. Sci. 2007, 8, 1001-1012. [CrossRef]

10. Holbrook, A.M.; Pereira, J.A.; Labiris, R.; McDonald, H.; Douketis, J.D.; Crowther, M.; Wells, P.S. Systematic overview of warfarin and its drug and food interactions. Arch. Intern. Med. 2005, 165, 1095-1106. [CrossRef] [PubMed]

11. Cesar, J.M.; Garcia-Avello, A.; Navarro, J.L.; Herraez, M.V. Aging and oral anticoagulant therapy using acenocoumarol. Blood Coagul. Fibrinolysis 2004, 15, 673-676. [CrossRef] [PubMed]

12. Ufer, M. Comparative pharmacokinetics of vitamin $\mathrm{K}$ antagonists: Warfarin, phenprocoumon and acenocoumarol. Clin. Pharmacokinet. 2005, 44, 1227-1246. [CrossRef] [PubMed]

13. Guan, A.Y.; Liu, C.L.; Li, M.; Zhang, H.; Li, Z.N.; Li, Z.M. Design, synthesis and structure-activity relationship of novel coumarin derivatives. Pest. Manag. Sci. 2011, 67, 647-655. [CrossRef] [PubMed]

14. Liu, C.; Guan, A.; Yang, J.; Chai, B.; Li, M.; Li, H.; Yang, J.; Xie, Y. Efficient approach to discover novel agrochemical candidates: Intermediate derivatization method. J. Agric. Food Chem. 2016, 64, 45-51. [CrossRef] [PubMed]

15. Guan, A.; Liu, C.; Yang, X.; Dekeyser, M. Application of the intermediate derivatization approach in agrochemical discovery. Chem. Rev. 2014, 114, 7079-7107. [CrossRef] [PubMed]

16. Yan, H.; Yin, W.; Liu, P.; Liu, J.; Hu, M.C.; Zhang, W. Palladium-catalyzed synthesis of 6-allylcoumarins using organotin reagents as multicoupling organometallic nucleophiles. Appl. Organomet. Chem. 2014, 28, 747-749. [CrossRef]

17. Zhang, R.; Xu, Z.; Yin, W.; Liu, P.; Zhang, W. Microwave-assisted synthesis and antifungal activities of polysubstituted furo[3,2-c]chromen-4-ones and 7,8,9,10-tetrahydro-6H-benzofuro[3,2-c]chromen-6-ones. Synth. Comm. 2014, 44, 3257-3263. [CrossRef] 
18. Yin, Q.; Yan, H.; Zhang, Y.; Wang, Y.; Zhang, G.; He, Y.; Zhang, W. Palladium-catalyzed synthesis of 8-allyl or 8-prenylcoumarins by using organotin reagents as multicoupling nucleophiles. Appl. Organomet. Chem. 2013, 27, 85-88. [CrossRef]

19. Gao, W.T.; Hou, W.D.; Zheng, M.R.; Tang, L.J. Clean and convenient one-pot synthesis of 4-hydroxycoumarin and 4-hydroxy-2-quinolinone derivatives. Synth. Comm. 2010, 40, 732-738. [CrossRef]

20. Risitano, F.; Grassi, G.; Foti, F.; Bilardo, C. A convenient synthesis of furo[3,2-c]coumarins by a tandem alkylation/intramolecular aldolisation reaction. Tetrahedron Lett. 2001, 42, 3503-3505. [CrossRef]

21. Dong, Y.; Shi, Q.; Liu, Y.N.; Wang, X.; Bastow, K.F.; Lee, K.H. Antitumor agents. 266. Design, synthesis, and biological evaluation of novel 2-(furan-2-yl)naphthalen-1-ol derivatives as potent and selective antibreast cancer agents. J. Med. Chem. 2009, 52, 3586-3590. [CrossRef] [PubMed]

22. Bernini, R.; Pasqualetti, M.; Provenzano, G.; Tempesta, S. Ecofriendly synthesis of halogenated flavonoids and evaluation of their antifungal activity. New J. Chem. 2015, 39, 2980-2987. [CrossRef]

23. Zhang, M.Z.; Chen, Q.; Mulholland, N.; Beattie, D.; Irwin, D.; Gu, Y.C.; Yang, G.F.; Clough, J. Synthesis and fungicidal activity of novel pimprinine analogues. Eur. J. Med. Chem. 2012, 53, 283-291. [CrossRef] [PubMed]

24. Liu, Y.; Chen, Z.; Ng, T.B.; Zhang, J.; Zhou, M.; Song, F.; Lu, F.; Liu, Y. Bacisubin, an antifungal protein with ribonuclease and hemagglutinating activities from Bacillus subtilis strain B-916. Peptides 2007, 28, 553-559. [CrossRef] [PubMed]

Sample Availability: Samples of the all target compounds are available from the authors.

(C) 2016 by the authors; licensee MDPI, Basel, Switzerland. This article is an open access article distributed under the terms and conditions of the Creative Commons Attribution (CC-BY) license (http://creativecommons.org/licenses/by/4.0/). 